\title{
Relações entre Nível Socioeconômico, Atividades Extracurriculares e Alfabetização
}

\author{
Neyfsom Carlos Fernandes Matias ${ }^{1}$ \\ ${ }^{1}$ Departamento de Psicologia da Universidade Federal de São João Del-Rei, São João Del-Rei, MG
}

\begin{abstract}
Resumo
Este estudo investigou as implicações do nível socioeconômico (NSE) na alfabetização, na inserção de crianças em atividades oferecidas por organizações não governamentais (ONGs) e os impactos dessas ações no desempenho escolar. A amostra da pesquisa foi composta por 560 estudantes do segundo ano de escolarização de oito escolas municipais de Belo Horizonte (MG), sendo que 301 eram do sexo masculino e 259 do sexo feminino. Os dados utilizados foram os resultados da Provinha Brasil e os NSEs das escolas. Os resultados indicaram que a taxa de alunos alfabetizados não ultrapassou $62,00 \%$ do total da amostra, a interferência do NSE no rendimento acadêmico e na vinculação dos estudantes com as ONGs. Conclui-se que o NSE impacta no desempenho escolar no início da alfabetização, na busca das famílias por locais para deixar suas crianças em segurança, como as ONGs, e as ações dessas instituições influenciaram indiretamente o processo de alfabetização.

Palavras-chave: nível socioeconômico, atividades extracurriculares, alfabetização, educação em tempo integral, organizações não governamentais
\end{abstract}

Relations between Socioeconomic Status, Extracurricular Activities and Literacy

\begin{abstract}
This study investigated the implications of socioeconomic status (SES) on literacy, in the inclusion of children in activities offered by non-governmental organizations (NGOs), and the impact of these actions on school performance. The research sample consisted of 560 students attending the second year of elementary school in eight municipal schools in Belo Horizonte, state of Minas Gerais, including 301 male and 259 female participants. The data used were the results of Provinha Brasil and the SES of the schools. The results indicated that the rate of literacy in students did not exceed $62 \%$ of the total sample and the interference of SES in the academic performance and in the students' association with NGOs. It is concluded that SES impacts school performance at the beginning of literacy, on the search by families for places to leave their children safely, such as NGOs, and the actions of these institutions indirectly influenced the literacy process.

Keywords: Socioeconomic status; extracurricular activities; literacy; full-time education; Non-governmental organizations
\end{abstract}

\section{Las Relaciones entre el Nivel Socioeconómico, las Actividades Extracurriculares y la Alfabetización}

\begin{abstract}
Resumen
Este estudio investigó implicaciones del nivel socioeconómico (NSE) en la alfabetización, también en la inclusión de niños en actividades que ofrecen las organizaciones no gobernamentales (ONGs) y el impacto de esas acciones en el desempeño escolar. La muestra fue compuesta por 560 estudiantes de segundo año escolar de ocho escuelas públicas de Belo Horizonte (MG), siendo 301 de sexo masculino y 259 de sexo femenino. Los datos utilizados fueron los resultados de la Provinha Brasil y los NSEs de las escuelas. Los resultados indicaron que el índice de alumnos alfabetizados no superó el 62,00\% del total de la muestra, la interferencia del NSE en el desempeño escolar y la vinculación de los estudiantes con las ONGs. Se concluye que el impacto del NSE en el desempeño escolar en la alfabetización temprana, la búsqueda de las familias por lugares para dejar a sus hijos seguros, tales como las ONG, y las acciones de esas instituciones, indirectamente influyeron en el processo de alfabetización.

Palabras-clave: nivel socioeconómico; actividades extracurriculares; alfabetización; educación en tiempo completo; organizaciones no gobernamentales
\end{abstract}

O contato com aparelhos eletrônicos, livros e brinquedos, entre outros objetos, e a supervisão das atividades escolares pelos responsáveis em casa contribuem significativamente para o processo de escolarização das crianças. A disponibilidade e o envolvimento do público infantil com esses utensílios dependem de questões socioeconômicas vinculadas à renda, à formação dos pais e ao local onde a família vive (Alves \& Soares, 2013; Alves, Soares, \& Xavier, 2014;
Marturano \& Elias, 2016; Matos, Nogueira, Resende, Nogueira, \& Alves, 2017; Oliveira et al., 2017; Oliveira \& Waldhelm, 2016; Pena \& Soares, 2016). Ou seja, na medida em que o nível socioeconômico (NSE) das famílias aumenta, maiores são as possibilidades de situações com potencial para impactar o desenvolvimento acadêmico dos estudantes. Essa associação acontece porque a aprendizagem se relaciona com as interações entre pessoas e objetos que atuam como promotores 
desenvolvimentais (Bronfenbrenner \& Morris, 2006; Vygotsky, 2003). Nesse sentido, crianças provenientes de contextos sociais culturalmente menos favorecidos também podem vivenciar situações que colaboram no desempenho escolar (Lahire, 1997). Estudos voltados para as variáveis socioeconômicas contribuem na elaboração e aperfeiçoamento de políticas públicas com foco no processo de escolarização, sobretudo, para discentes de estratos sociais menos favorecidos (Carnoy, Khavenson, Fonseca, Costa, \& Marotta, 2015; Fonseca \& Namen, 2016).

O número de programas que atendem alunos fora do horário escolar, a partir do oferecimento de atividades esportivas, culturais e pedagógicas aumentou no Brasil (Alves, Amparo, Cardenas, Chaves, \& Oliveira, 2007; Azevedo \& Betti, 2014; Silva \& Silva, 2013). Essas iniciativas são promovidas por ONGs que se transformaram em parceiras de órgãos governamentais na ampliação da jornada escolar brasileira (Leite \& Carvalho, 2016; Schimonek, 2015). Nos últimos anos, houve empenho na articulação entre instituições de ensino e organizações sociais no fomento desse tipo de educação (Azevedo \& Betti, 2014). Isso está em sintonia com a ideia de que os processos educativos também ocorrem para além das salas de aula e da necessidade de oferecer locais para a permanência das crianças enquanto seus responsáveis estão no trabalho (Silva \& Silva, 2013).

Esse tipo de articulação aconteceu na cidade de Belo Horizonte (BH/MG) em 2010 (Prefeitura Municipal de Belo Horizonte [PBH], 2010), quando a Secretaria Municipal de Educação (SMED) passou a estabelecer convênios com entidades que já atendiam crianças e adolescentes, por meio da política de assistência social, a fim de executar parte do Programa Escola Integrada. O programa promove atividades extracurriculares, dentro da escola e em espaços próximos a ela, como oficinas de esporte, recreação, dança, informática e auxílio à execução do para casa. Na concepção da Escola Integrada, a educação ultrapassa os muros escolares e a frequência nessas atividades contribui para o aumento do desempenho escolar dos estudantes (Leite \& Carvalho, 2016). Essa premissa está em sintonia com apontamentos de pesquisadores internacionais (Cooper, Valentine, Ney, \& Lindsay, 1999; Mahoney, Cairns, \& Farmer, 2003; Mahoney, Lord, \& Carryl, 2005; Springer \& Diffily, 2012).

Cooper et al. (1999) destacam a participação em programas extracurriculares como influência positiva no desempenho acadêmico. Essa interferência se deve a variáveis relacionadas a organização, desenvolvimento, foco das atividades e interações entre os participantes e destes com os educadores. Mahoney et al. (2003) identificaram que essas atividades atuam no aperfeiçoamento da competência interpessoal e da iniciativa, favorecendo a mudança nos objetivos de vida e, consequentemente, influenciando o sucesso educacional. Para esses pesquisadores, estudantes de estratos sociais menos favorecidos se beneficiam das atividades extracurriculares e elas estão vinculadas ao status educacional na idade adulta. Mahoney et al. (2005) corroboram esses dados ao evidenciarem esses projetos como oportunidade ímpar na capacidade de promoção do sucesso acadêmico. Isso pode ser explicado pelo fato de essas pessoas, nesses contextos, utilizarem a maior parte do seu tempo em atividades relacionadas a escola, jogos e brincadeiras supervisionados por adultos. Essas informações indicam o ambiente dos programas extracurriculares como rico em interações com potencial para promover $\mathrm{o}$ desenvolvimento, remediando os danos causados pela ausência de recursos socioeconômicos e de acompanhamento escolar dessas crianças.

No Brasil, foram elencados resultados semelhantes. O Fundo das Nações Unidas para a Infância (UNICEF) (2010) desenvolveu uma pesquisa em 26 cidades com intuito de descobrir as causas dos avanços no Índice de Desenvolvimento da Educação Básica (IDEB). A ampliação do tempo em atividades extracurriculares, como o apoio pedagógico no contraturno, sendo o reforço escolar a principal estratégia, juntamente com atividades de esporte e lazer, foi identificada como a principal razão desse ganho. As informações desse estudo confirmaram achados anteriores de outra pesquisa (UNICEF, 2008) e reforçam a importância das atividades complementares no aumento dos índices escolares. Não por acaso, o governo federal privilegiou a implantação do Programa Mais Educação nas escolas com baixos IDEBs (Pio \& Czernisz, 2015). Assim, observa-se que o envolvimento dos estudantes em atividades extracurriculares tem implicações positivas nas avaliações educacionais. Esses efeitos são resultados da articulação entre a participação dos estudantes em atividades artísticas, culturais e pedagógicas, bem como do auxílio aos discentes na execução da tarefa para casa (Cooper et al., 1999; Mahoney et al., 2003; Silva \& Ehrenberg, 2017; Springer \& Diffily, 2012; UNICEF, 2008; 2010).

Pelas considerações apresentadas, é possível verificar relações entre o NSE e a aprendizagem escolar. 
No entanto, as investigações sobre essa questão têm como foco alunos a partir do quarto ano de escolarização (Alves \& Soares, 2013; Alves et al., 2014). Há uma lacuna quanto a pesquisas sobre esse aspecto até o segundo ano do ensino fundamental. A busca por locais, como as ONGs, por responsáveis para a permanência das crianças, quando não estão na escola, também é influenciada por questões socioeconômicas (Schimonek, 2016; Soares, Brandolin, \& Amaral, 2017). Em contrapartida, há indícios de a frequência em atividades como as oferecidas por essas instituições contribuírem com o desempenho escolar (Springer \& Diffily, 2012; UNICEF, 2008; 2010). A partir desses pressupostos, este estudo teve o objetivo de investigar se as implicações do NSE na aprendizagem escolar são identificadas a partir de resultados de uma avaliação governamental da alfabetização. Especificamente, o trabalho: levantou a taxa de crianças alfabetizadas no final do segundo ano de escolarização; investigou a influência do NSE no desempenho escolar; pesquisou a associação entre NSE e inserção de crianças em atividades oferecidas por ONGs e, por fim, verificou a interferência dessa participação no desempenho escolar.

\section{Método}

Trata-se de um estudo exploratório-descritivo que combinou abordagem quantitativa e pesquisa documental. A pesquisa exploratória oferece a possibilidade de familiarização com problemas a fim de explicitá-los e contribuir na elaboração de hipóteses. O desenho descritivo permite descrever as características de determinadas populações e situações (Gil, 2010).

\section{Participantes}

Foram selecionados, a partir de uma lista disponibilizada pela Secretaria Municipal de Educação (SMED), somente os estudantes que realizaram o ciclo da avaliação Provinha Brasil (PB) e eram provenientes de escolas com alunos vinculados à ONGs. A partir das listagens de atendidos por essas instituições, foram verificados os seus frequentadores. Para ser incluído no grupo de participantes das entidades, o estudante deveria estar relacionado em todos os relatórios de atendimento, enviados à Secretaria Municipal de Assistência Social (SMAAS) pelas organizações sociais, no interstício de fevereiro a novembro de 2009. O grupo de não participantes foi definido a partir da confrontação das listas de estudantes que realizaram a PB e de frequentadores das organizações sociais.
Com base nesses parâmetros, a amostra do estudo se constituiu com 560 participantes. Todos estavam matriculados no $2^{\circ}$ ano de escolarização em oito escolas municipais, com alunos frequentando oito ONGs. Desses, 301 (53,75\%) eram do sexo masculino e 259 $(46,25 \%)$, do sexo feminino. Sessenta e sete $(12,00 \%)$ participavam das atividades oferecidas pelas ONGs. Do total de frequentes nas instituições, $54,00 \%$ eram do sexo masculino e $46,00 \%$ do sexo feminino.

\section{Instrumentos e Materiais}

Os Planos de Trabalho e Relatórios de Supervisão foram utilizados para caracterizar as atividades proporcionadas pelas ONGs, averiguar questões como formação dos educadores envolvidos nos atendimentos, organização, estrutura e desenvolvimento das ações. Essas informações foram registradas em uma ficha de coleta de dados. A escrita desses planos era de responsabilidade das instituições, com o acompanhamento de um técnico, cuja formação exigida para o trabalho era de nível superior em Psicologia ou Serviço Social, da SMAAS, responsável pela supervisão dos atendimentos. Esse monitoramento era desenvolvido por meio de visitas às entidades, reuniões com coordenadores pedagógicos e educadores. Essas ações eram registradas em relatórios.

Os resultados da Provinha Brasil (PB), destinada aos estudantes do segundo ano de escolarização, foram usados como medida de alfabetização. A administração dessa avaliação era de responsabilidade da SMED e ocorria em duas etapas, abrangendo o ciclo da prova: no início do ano e no fim do segundo semestre letivo (Brasil, 2008; 2009). O objetivo desse instrumento é "avaliar o nível de alfabetização dos educandos nos anos iniciais do ensino fundamental" (Brasil, 2009, p. 8). Os escores brutos da PB são utilizados para determinar o grau de alfabetização do aluno, dividido em cinco níveis, definidos a partir do número de acertos. Na primeira etapa, os índices eram apurados da seguinte forma: Nível 1, até 10 acertos; Nível 2, de 11 a 15 acertos; Nível 3, de 16 a 18 acertos; Nível 4, de 19 a 22 acertos; Nível 5, de 23 a 24 acertos. Na segunda etapa, a dificuldade na avaliação aumenta: Nível 1, até 7 acertos; Nível 2, de 8 a 11 acertos; Nível 3, de 12 a 18 acertos; Nível 4, de 19 a 21 acertos; e Nível 5, de 22 a 24 acertos.

Foram utilizados ainda os NSEs apurados das escolas. A elaboração desse índice se dá a partir de pesquisa realizada pela SMED sobre a renda familiar e a disposição de utensílios em casa. Esse escore é 
calculado de forma semelhante ao adotado pelo Critério Brasil (Matos et al., 2017; Alves et al., 2014).

\section{Procedimentos}

O pesquisador entrou em contato com as secretarias municipais de Educação e Adjunta de Assistência Social (SMAAS), da Prefeitura Municipal de Belo Horizonte $(\mathrm{PBH})$, para verificar a viabilidade de acessar os dados para a efetivação do estudo. Em seguida, foram realizadas reuniões com os gestores públicos para esclarecer os objetivos da pesquisa e a forma como as informações seriam utilizadas. Os gerentes dos órgãos responsáveis pelas informações foram informados acerca dos procedimentos que seriam adotados e como os dados seriam analisados. O propositor do estudo se comprometeu a codificar as informações no intuito de manter o anonimato de todos os envolvidos: escolas, estudantes e ONGs. Assim, o estudo foi desenvolvido em consonância com princípios éticos e aconteceu após a anuência dos gestores públicos.

A SMED disponibilizou um banco de dados com as escolas de origem, com seus respectivos NSEs, os níveis alcançados na PB pelos alunos e o sexo dos estudantes das escolas municipais da região Leste de BH. A escolha dessa área ocorreu pelo critério de conveniência. A SMAAS, secretaria responsável pela parceria com as ONGs, por sua vez, proporcionou o acesso aos documentos nos arquivos da repartição pública que coordenava os convênios com as ONGs.

\section{Análise dos Dados}

$\mathrm{Na}$ análise dos documentos, inicialmente, foi realizada uma leitura flutuante visando estabelecer contato com o material. Em seguida, essas informações foram organizadas, na ficha de coleta de dados, e seus conteúdos examinados, com o objetivo de identificar se as atividades oferecidas pelas ONGs poderiam ser enquadradas em duas categorias. A primeira corresponde ao atendimento do tipo acadêmico, na qual foram incluídas todas as instituições que organizavam os atendimentos com atividades como o auxílio ao para casa, o reforço escolar e com os horários distribuídos como os de uma escola. A segunda corresponde ao tipo recreativo, caracterizando o atendimento das entidades voltadas para questões artísticas, lúdicas e recreativas. Além disso, a consulta ao material objetivou identificar o nível de escolaridade dos educadores e a existência de articulação entre organizações sociais e escolas. A opção por esses critérios se deu a partir das orientações de Bardin (2009) para o desenvolvimento de pesquisas de análise de conteúdo.
Quanto aos resultados da PB, a princípio, foram apurados os níveis da amostra total do estudo. Após esse levantamento, foi criada a variável alfabetização, com as categorias não alfabetizado e alfabetizado, considerando os índices alcançados pelos alunos da seguinte forma: a primeira compreende os níveis de 1 a 3 e a segunda, os níveis 4 e 5 . A escolha por essa categorização se deu pela viabilidade que esse sistema proporcionou no levantamento daqueles alunos que foram alfabetizados no final do segundo ano de escolarização e com base nas concepções de alfabetização e letramento adotadas no âmbito da PB. Quando os estudantes alcançavam o nível quatro, eles demonstravam as habilidades que caracterizavam a consolidação do processo de alfabetização. Além disso, os alunos deveriam estar "entre os níveis 4 e 5 no final do segundo ano de escolarização" (Brasil, 2009, p. 17). Ou seja, alfabetizados "até, no máximo, os oito anos de idade” (Brasil, 2007, p. 5).

Os dados acerca do NSE foram categorizados em uma escala de 1 a 5 , em sintonia com os critérios estabelecidos pela SMED. Assim, respectivamente, os níveis corresponderam a: até 2,00; entre 2,01 e 4,00; entre 4,01 e 6,00; entre 6,01 e 8,00; e entre 8,01 e 10,00, sendo que, quanto maior a faixa, maior a renda das famílias dos estudantes (Secretaria Municipal de Educação [SMED], 2014). A opção por não utilizar o índice apurado de cada instituição se deu em função de manter o sigilo quanto à identificação das escolas.

A fim de alcançar os objetivos do estudo, os participantes foram divididos da seguinte forma: por escolas, por NSE das instituições de ensino, por participantes e não participantes das ONGs e pelas organizações que frequentavam. Os níveis da PB foram analisados a partir dos testes não paramétricos de Kruskal-Wallis, com medidas a posteriori com o teste $U$ de Mann-Whitney, e o teste de qui-quadrado para identificar a associação entre NSE e vinculação com as ONGs. Nas análises de diferenças entre as escolas, com o teste $U$ de Mann-Whitney, foi aplicada a correção de Bonferroni e o valor de $p$ adotado foi de 0,0017; nas outras, o nível de significância foi de $p<$ 0,050. Todas as análises se deram no Programa Statistical Package for the Social Sciences SPSS.

\section{Resultados}

\section{Categorização das Atividades Oferecidas pelas ONGs}

As atividades de seis ONGs foram categorizadas como do tipo acadêmicas, apresentando conjuntos de 
ações voltadas predominantemente para a escolarização - apoio à execução do para casa e reforço escolar (ONG-1, ONG-2, ONG-3, ONG-4, ONG-5 e ONG6). A recreação era proporcionada nos intervalos das oficinas realizadas em espaços semelhantes aos de salas de aula formais, com quadro-negro e carteiras escolares. Em duas organizações (ONG-7 e ONG-8), o atendimento concentrava-se em atividades culturais e artísticas, caracterizadas como do tipo recreativas. O público prioritário de todas as instituições era de crianças provenientes de famílias com baixo poder aquisitivo e funcionavam em comunidades com alta vulnerabilidade social. Os estudantes frequentavam o conjunto de atividades oferecidas, de segunda a sexta-feira, durante quatro horas diárias, em horário alternado ao da escola. A maioria dos educadores tinha formação de nível médio. Não foram identificadas ações conjuntas entre ONGs e escolas.

\section{Desempenho na Provinha Brasil e Vinculação com as ONGs}

Por meio da categorização alfabetizados e não alfabetizados, foi possível observar que, a partir da amostra total deste estudo $(N=560)$, a taxa de estudantes alfabetizados no final do segundo ano foi de $61,80 \%$ $(n=346)$. A Tabela 1 apresenta a frequência e a porcentagem de estudantes nas duas categorias, divididos por escolas com sua faixa de NSE, o resultado dos testes de Kruskal-Wallis, $U$ de Mann-Whitney e os postos alcançados pelos grupos.

Para investigar a influência do NSE no desempenho escolar, foi realizado um teste de Kruskal-Wallis, considerando os níveis 1 (ESC-1, ESC-2), 2 (ESC-3,

Tabela 1

Número de Alfabetizados e Não Alfabetizados por Escolas e Postos Médios Alcancados nas Análises

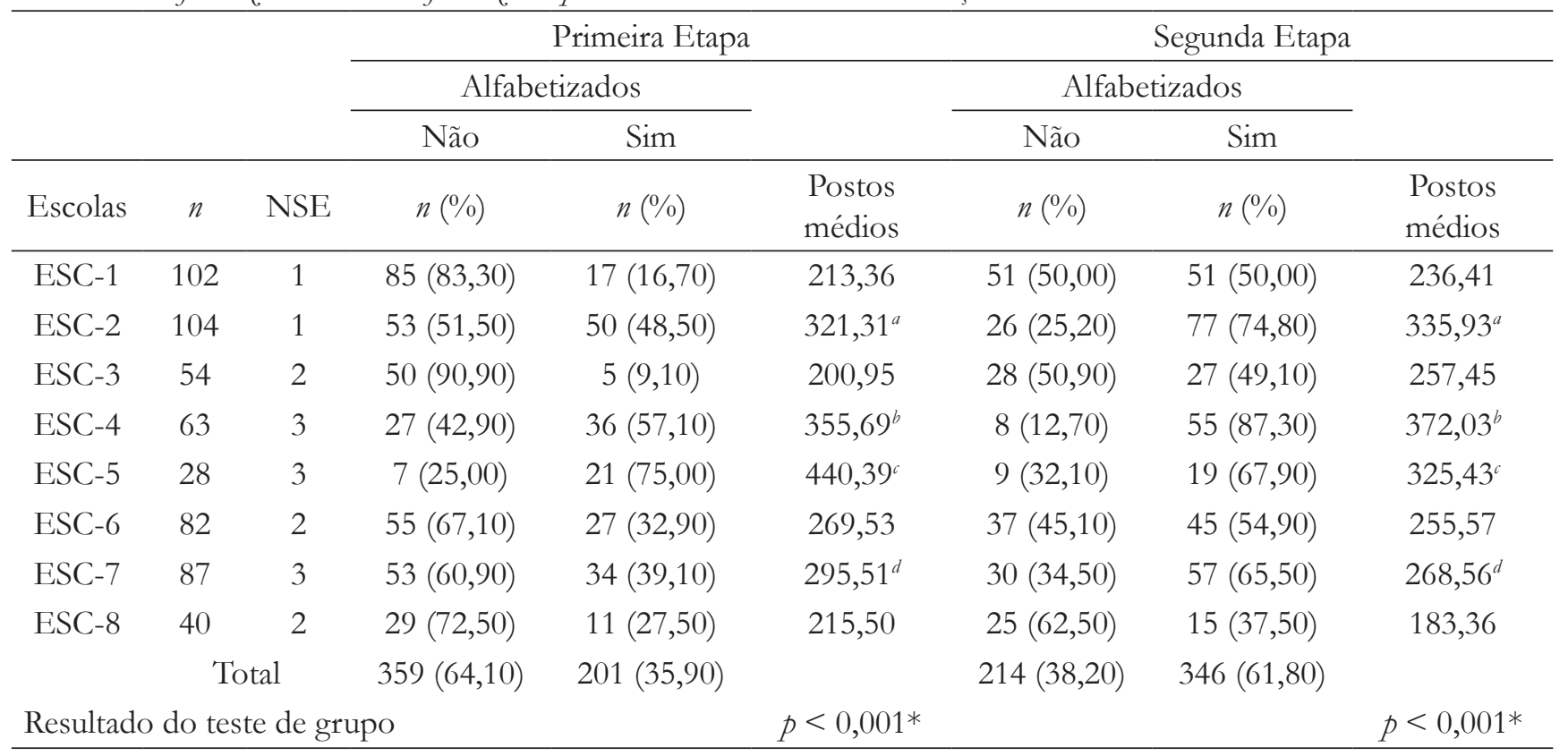

Nota. $n=$ número de estudantes. NSE = Nível Socioeconômico.

* Teste de Kruskal-Wallis.

Teste U de Mann-Whitney com correção de Bonferrone $p=0,0017$ :

$a=$ Significativamente diferente, na primeira etapa, em relação a ESC-1, ESC-3, ESC-5 e ESC-8, e na segunda etapa a ESC-1, ESC-6, ESC-7 e ESC-8.

$b=$ Significativamente diferente, na primeira etapa, em relação a ESC-1, ESC-3, ESC-4 e ESC-8, e na segunda etapa em relação a ESC-1, ESC-3, ESC-6, ESC-7 e ESC-8.

$c=$ Significativamente diferente, na primeira etapa, em relação a ESC-1, ESC-2, ESC-3, ESC-6, ESC-7 e ESC-8, e na segunda etapa em relação a ESC-8.

$d=$ Significativamente diferente, na primeira etapa, em relação a ESC-1 e ESC-3. 
ESC-6 e ESC-8) e 3 (ESC-4, ESC-5 e ESC-7). O resultado indicou diferença significativa na segunda etapa. As medidas a posteriori com o teste $U$ de Mann-Whitney indicou significância estatística entre os níveis 1 (Mediana $=4,00)$ e 2 (Mediana $=3,00)$, favorável ao nível $1 \mathrm{com}$ postos mais altos; e entre 2 (Mediana = 3,00) e 3 (Mediana $=4,16$ ), em que o nível 3 alcançou postos mais altos.

Foi realizada uma análise considerando as escolas, a fim de verificar quais delas se sobressairiam. $\mathrm{Na}$ Tabela 1, encontram-se os resultados desses testes e observa-se que a ESC-2 (Mediana = 5,00), com NSE 1 destaca-se em relação a ESC-1 (Mediana = 3,50), ESC-6 $($ Mediana $=4,00)$, ESC-7 $($ Mediana $=4,00)$ e ESC-8 (Mediana $=3,00)$. Escolas com maior NSE alcançaram postos mais altos em relação a outras, como é o caso da ESC-4 (Mediana = 5,00), com NSE 3, comparado a ESC-1 (Mediana $=3,50)$, ESC-3 (Mediana = 3,00), ESC-6 (Mediana $=4,00)$, ESC-7 $($ Mediana $=4,00) \mathrm{e}$ ESC-8 (Mediana 3,00).

A apuração dos alunos vinculados a ONGs indicou que, na ESC-1 e ESC-2, concentravam-se o maior número de participantes das atividades extracurriculares. A investigação da associação entre NSE e participação nas ONGs indicou que quanto menor o fator econômico da escola, maior o número de estudantes vinculados às instituições sociais $(p<0,001)$. Esse resultado se repetiu na apuração, considerando os três
NSEs. Na Tabela 2, estão as frequências de participantes nas ONGs, divididos por escolas, com seus respectivos NSEs, e o resultado do teste de qui-quadrado.

A Tabela 3 apresenta a frequência de estudantes divididos entre as categorias não alfabetizados e alfabetizados agrupados entre não participantes e participantes das ONGs, pelas organizações frequentadas e os postos alcançados nas análises. Entre os frequentes nessas atividades, 55,20\% terminaram o ano alfabetizados. A taxa de alfabetizados, entre os participantes das ONGs, comparada com os não participantes, é menor em 6,80\%. A investigação sobre o desempenho escolar pesquisou a existência de diferença entre os estudantes divididos entre não participantes e participantes, considerando a amostra total e, nas entidades com no mínimo cinco estudantes, em sintonia com os critérios das análises estatísticas realizadas, e não participantes e participantes divididos por ONGs. Nenhuma dessas análises destacou diferença significativa entre os grupos $(p>0,050)$.

Como os resultados das instituições de ensino indicaram diferença significativa entre elas, foram realizadas análises entre participantes e não participantes das ONGs por escolas. Com o intuito de não violar regras estatísticas nessas análises, foram consideradas apenas as escolas que possuíam no mínimo cinco estudantes vinculados a uma mesma ONG. Assim, os dados foram separados por escolas e respectivas organizações

Tabela 2

Participação nas Atividades das ONGs por Escolas

\begin{tabular}{|c|c|c|c|c|c|}
\hline \multirow[b]{2}{*}{ Escolas } & \multirow[b]{2}{*}{ NSE } & \multicolumn{2}{|c|}{$\begin{array}{l}\text { Participa nas atividades } \\
\text { promovidas pelas ONGs }\end{array}$} & \multirow[b]{2}{*}{ Total } & \multirow[b]{2}{*}{$p^{*}$} \\
\hline & & Não & Sim & & \\
\hline & & $\mathrm{n}(\%)$ & $\mathrm{n}(\%)$ & $\mathrm{n}(\%)$ & \\
\hline ESC-1 & 1 & $78(76,50)$ & $24(23,50)$ & $102(18,20)$ & \\
\hline ESC-2 & 1 & $78(75,70)$ & $25(24,30)$ & $103(18,40)$ & \\
\hline ESC-3 & 2 & $50(90,90)$ & $5(9,10)$ & $55(9,80)$ & \\
\hline ESC-4 & 3 & $60(95,20)$ & $3(4,80)$ & $63(11,30)$ & \\
\hline ESC-5 & 3 & $25(89,30)$ & $3(10,70)$ & $28(5,00)$ & $<0,001$ \\
\hline ESC-6 & 2 & $79(96,30)$ & $3(3,70)$ & $82(14,60)$ & \\
\hline ESC-7 & 3 & $85(97,70)$ & $2(2,30)$ & $87(15,50)$ & \\
\hline \multirow[t]{2}{*}{ ESC-8 } & 2 & $38(95,00)$ & $2(5,00)$ & $40(7,10)$ & \\
\hline & Total & $493(88,00)$ & $67(12,00)$ & $560(100,00)$ & \\
\hline
\end{tabular}

Nota. ONGs = organizações não governamentais. NSE = nível socioeconômico.

* Teste de qui-quadrado. 
Tabela 3

Número de Estudantes, Participantes e não Participantes das ONGs, Alfabetizados

\begin{tabular}{|c|c|c|c|c|c|c|}
\hline & \multicolumn{3}{|c|}{ Primeira Etapa } & \multicolumn{3}{|c|}{ Segunda Etapa } \\
\hline & \multicolumn{2}{|c|}{ Alfabetizados } & \multirow[b]{2}{*}{ Postos médios } & \multicolumn{2}{|c|}{ Alfabetizados } & \multirow[b]{2}{*}{ Postos médios } \\
\hline & $\begin{array}{l}\text { Não } \\
n(\%) \\
\end{array}$ & $\begin{array}{c}\text { Sim } \\
n(\%)\end{array}$ & & $\begin{array}{l}\text { Não } \\
n(\%) \\
\end{array}$ & $\begin{array}{c}\text { Sim } \\
n(\%)\end{array}$ & \\
\hline Não Part. & $311(63,10)$ & $182(36,90)$ & 283,74 & $184(37,30)$ & $309(62,70)$ & 284,07 \\
\hline ONG-1 & $21(87,50)$ & $3(12,50)$ & 194,73 & $15(62,50)$ & $9(37,50)$ & 194,90 \\
\hline ONG-2 & $16(69,60)$ & $7(30,40)$ & 262,91 & $8(34,80)$ & $15(65,20)$ & 277,63 \\
\hline ONG-3 & $3(50,00)$ & $3(50,00)$ & 383,67 & $2(33,30)$ & $4(66,70)$ & 323,50 \\
\hline ONG-4 & $1(20,00)$ & $4(80,00)$ & 400,60 & $1(20,00)$ & $4(80,00)$ & 362,40 \\
\hline ONG-5 & $3(100,00)$ & $0(0,00)$ & 188,67 & $2(66,70)$ & $1(33,30)$ & 240,67 \\
\hline ONG-6 & $1(50,00)$ & $1(50,00)$ & 358,00 & $0(0,00)$ & $2(100,00)$ & 377,50 \\
\hline ONG-7 & $1(50,00)$ & $1(50,00)$ & 230,75 & $2(100,00)$ & $0(0,00)$ & 78,75 \\
\hline ONG-8 & $2(100,00)$ & $0(0,00)$ & 213,25 & $0(0,00)$ & $2(0,00)$ & 291,00 \\
\hline Total & $359(64,10)$ & $201(35,90)$ & & $214(38,20)$ & $346(61,80)$ & \\
\hline \multicolumn{2}{|c|}{ Resultado do teste de grupo* } & & $p=0,055$ & & & $p=0,083$ \\
\hline
\end{tabular}

Nota. $\mathrm{PB}=$ Provinha Brasil. Não Part. = número de não participantes das ONGs.

* Teste de Kruskal-Wallis.

que atendiam seus alunos: ESC-1 com ONG-1 e ESC-2 com ONG-2. As análises a partir do teste $U$ de Mann-Whitney, não destacou significância estatística entre esses grupos nos níveis da PB ( $p>0,050)$.

\section{Discussão}

Os resultados deste estudo indicaram que a taxa de alunos alfabetizados no segundo ano de escolarização não ultrapassou $62,00 \%$ do total da amostra, a interferência do NSE no desempenho escolar e na vinculação dos estudantes com as ONGs. O conjunto das atividades em seis dessas instituições foi caracterizado como do tipo acadêmicas e em duas como recreativas. Os dados apurados indicaram efeitos indiretos na alfabetização da participação nas atividades oferecidas por essas entidades. Essas informações apontam questões importantes a serem discutidas.

A presente pesquisa teve um delineamento exploratório-descritivo, a partir da combinação de dados quantitativos e qualitativos. O primeiro desenho permitiu apurar a taxa de alfabetização e verificar a existência ou não de diferenças significativas nos níveis da $\mathrm{PB}$, com a utilização de testes não paramétricos - análises indicadas no trato de dados ordinais - entre os estudantes divididos por escolas, por NSE das instituições de ensino e pela participação nas ONGs. Há de se ressaltar ainda que a categorização alfabetizados e não alfabetizados dos dados permitiu visualizar o objeto avaliado pela PB: a alfabetização. O delineamento descritivo ofereceu as possibilidades de demonstrar que a taxa de estudantes alfabetizados ficou aquém do previsto (Brasil, 2009; 2007) e de caracterizar as atividades frequentadas pelos estudantes nas organizações sociais.

A utilização dessas metodologias foi fundamental para alcançar os objetivos do estudo e contribuiu para a identificação de um pressuposto relacionado às interferências das questões socioeconômicas no processo de escolarização. Os dados destacaram que o NSE impacta no desempenho escolar no segundo ano de escolarização, na inserção em atividades desenvolvidas por ONGs que, por sua vez, promovem impactos indiretos na alfabetização. Em resposta aos objetivos das pesquisas exploratórias (Gil, 2010), os resultados levantaram e comprovaram três hipóteses, utilizadas para fundamentar essa pressuposição.

A primeira é a de que o NSE impacta no desempenho escolar no segundo ano de alfabetização. Esse dado demonstra algo novo pelo fato de a maioria das pesquisas sobre essa relação pautar-se em informações provenientes de estudantes a partir do quarto ano de escolarização (Alves \& Soares, 2013; Alves et al., 2014). 
Porém, há de se considerar que esse índice per se não explica o resultado das escolas com maior NSE. Como esse fator possibilita o acesso a recursos diversos, há uma interferência em aspectos desenvolvimentais articulados com as habilidades cognitivas importantes para a aprendizagem escolar, sobretudo por meio das interações sociais (Bronfenbrenner \& Morris, 2006; Vygotsky, 2003).

Existe uma associação direta entre a renda e anos de escolaridade no Brasil. Assim, famílias com alto NSE são compostas por pais com maior nível de escolarização com hábitos que colaboram na formação dos filhos (Matos et al., 2017). Dentre outros, destacam-se a leitura de livros e de jornais, a frequência a locais como teatros, cinemas e centros culturais. Além disso, esses responsáveis acompanham as tarefas escolares e o desempenho dos estudantes. Essas atividades têm implicações positivas no processo de escolarização (Carneiro, Silva, Rizzoli, \& Silva, 2015; Monteiro \& Santos, 2013; Oliveira et al., 2017). O desenvolvimento de programas destinados aos pais e responsáveis visando à prática dessas ações pode colaborar no desempenho dos estudantes, independentemente da renda das famílias.

O fato da ESC-2, com NSE 1, ter se sobressaído em relação a outras escolas na mesma faixa e também com maior nível levantou a possibilidade dos aspectos vinculados a essa instituição de ensino, por exemplo, projetos institucionais, papel da direção e formação dos professores terem superado as implicações das questões sociodemográficas (Pena \& Soares, 2016). A princípio, esse resultado refutaria a primeira hipótese elencada. No entanto, o fato da ESC-4 ter se destacado em relação à ESC-3, nas comparações com as outras em que houve significância favorável à ESC-2, e de ela ter alcançado postos mais altos reforça essa primeira suposição. A evidência da ESC-2 ressalta a importância de políticas voltadas para as escolas considerando os aspectos sociais dos estudantes (Alves \& Soares, 2013). As secretarias de educação municipais, estaduais e o Ministério da Educação devem oferecer ações para amenizar interferências ocasionadas pelo background familiar. Isso pode acontecer a partir de estímulos à formação docente, bem como de elaboração de estratégias de gestão pelos diretores que colaborem com clima escolar positivo (Oliveira \& Waldhelm, 2016). A PBH considera a necessidade de ações nesse sentido ao definir valores de repasses de verbas com base no NSE da escola, sendo que aquelas com menor índice recebem mais (SMED, 2014). No entanto, devido às limitações deste estudo, não foi possível aprofundar nas influências dessa política nem identificar outras variáveis explicativas da diferença encontrada, favorável à ESC-2, ficando isso a ser contemplado em estudos futuros.

A segunda hipótese trata do fato de que o NSE influencia na busca de locais para a permanência das crianças no horário alternado ao da escola. Foi observado que nas escolas com baixo NSE havia maior concentração de estudantes vinculados às ONGs. Essas instituições estavam localizadas em regiões de vulnerabilidade social e visavam ao atendimento de crianças provenientes de grupos com baixo poder aquisitivo. Nesse sentido, observa-se a interferência do índice socioeconômico na busca das famílias por locais para manter seus filhos, na maioria das vezes, para que ambos os pais possam trabalhar. Não é por acaso que as organizações sociais se voltavam para a proteção social, prevenindo o envolvimento das crianças com questões ilícitas e insalubres, como o tráfico de drogas e o trabalho infantil (Alves et al., 2007).

Observa-se que os atendimentos proporcionados às crianças, em seis das oito ONGs, pautaram-se em atividades do tipo acadêmicas, com uma estrutura próxima à das aulas formais. Isso levantou a possibilidade de haver resultados superiores dos estudantes frequentes nessas instituições na PB, considerando-se o reforço aos conteúdos escolares. Estudos têm evidenciado a participação em atividades com essas características como promotora do desempenho escolar (Mahoney et al., 2005; Silva \& Ehrenberg, 2017; UNICEF, 2010, 2008), sobretudo das populações de estrato social menos favorecido, como é o caso dos estudantes vinculados às ONGs. Torna-se pertinente destacar que, apesar da aderência a essa forma de atendimento por diversas organizações sociais, o foco na escolarização não deveria ser concebido como princípio dessas entidades, nem mesmo de atender às demandas das escolas, por elas se voltarem para os aspectos protetivos da infância.

Os dados indicam a possibilidade da participação nessas atividades interferir no desempenho escolar dos estudantes. Mesmo com foco na proteção social, as atividades oferecidas por ONGs têm implicações indiretas na alfabetização, sendo essa a terceira hipótese apurada pelo estudo. A taxa de alfabetizados dos participantes das atividades extracurriculares foi inferior aos não participantes. No entanto, não houve diferença significativa nos níveis da PB entre esses grupos, mesmo nas análises por escolas. Isso indica que as organizações sociais têm implicações implícitas no desempenho escolar. Apesar 
da inacessibilidade de informações precisas acerca das diferenças econômicas entre os participantes e não participantes nas escolas, é possível fazer essa inferência.

A afirmação da presença de impactos indiretos torna-se viável a partir do dado de que escolas com menor NSE tiveram baixo desempenho na PB, como já demonstrado em outros estudos que discutem as implicações do NSE no desempenho escolar (Alves \& Soares, 2013; Alves et al., 2014; Matos et al., 2017; Oliveira \& Waldhelm, 2016; Pena \& Soares, 2016) e do fato das ONGs atenderem crianças provenientes de famílias com baixo poder aquisitivo. Elas tinham características que levariam a um rendimento acadêmico empobrecido. Assim, a ausência de diferença significativa entre esses grupos indica a possibilidade das ONGs interferirem no desempenho escolar dos estudantes. Isso foi viabilizado pela oportunidade proporcionada a esse público de desenvolver tarefas relacionadas ao processo de escolarização no contexto das organizações sociais. No entanto, essas considerações conduzem a uma questão: por que esses alunos não se destacaram?

O fato dos participantes das instituições não se sobressaírem, quando comparados aos outros, pode estar vinculado à falta de capacitação dos educadores, à organização das atividades e à desarticulação do que é oferecido pelas ONGs com as escolas. Alves et al. (2007) demonstraram que os profissionais envolvidos nesse tipo de atendimento carecem de formação para o serviço. A ausência de propostas pedagógicas sólidas, totalmente dissociadas dos conteúdos escolares, são características marcantes dos atendimentos oferecidos por entidades sociais. Mesmo assim, o cotidiano dessas atividades pode atenuar os efeitos da carência de interações proporcionadas por recursos relacionados ao NSE. Nesse sentido, esses atendimentos são responsáveis indiretamente pelo desempenho escolar dos estudantes. Porém, não se deve atribuir a essas organizações a função de reforçar conteúdos acadêmicos, mas sim de desenvolver seus trabalhos a partir de uma concepção de educação para além dos conteúdos escolares. Soma-se a essas questões o fato de que o aporte financeiro recebido pelas ONGs, para arcar com os atendimentos durante a vigência do convênio via SMAAS, era insuficiente (PBH, 2001).

Caso os atendimentos estivessem em outras condições, o resultado poderia ter sido diferente, no sentido de destacar os participantes em relação aos não participantes em sintonia com outros estudos (Silva \& Ehrenberg, 2017; Springer \& Diffily, 2012). Reafirma-se os resultados apresentados não indicam que as ONGs têm uma atuação inócua. Muito pelo contrário, elas proporcionam efeitos positivos quanto à proteção social de crianças. Assim, a função de proteger se sobressai e a de contribuir na escolarização é contemplada indiretamente com a oferta de ações artísticas, esportivas e culturais, em uma perspectiva ampla de educação (Schimonek, 2015). No entanto, isso não exime o Estado da responsabilidade de desenvolver políticas públicas para esse público tanto dentro, como fora das escolas.

Os dados utilizados na elaboração deste estudo se referem a uma época em que as instituições compunham a rede de atendimento ao público infantojuvenil da política de assistência social da Prefeitura Municipal de Belo Horizonte. Por isso, a formalização dos convênios entre ONGs e município se pautou em objetivos que visavam à proteção social, ao fortalecimento de vínculos e à convivência social (Ministério do Desenvolvimento Social e Combate à Fome/Conselho Nacional de Assistência Social, 2009). A ênfase nos conteúdos escolares não estava em sintonia com o prescrito para os atendimentos. Nesse sentido, não havia obrigação das instituições de utilizar esse formato no desenvolvimento das suas ações.

A partir do ano de 2011, essas organizações se tornaram parceiras do Programa Escola Integrada e um dos objetivos era promover maior articulação entre ONGs e escolas (PBH, 2010). Além disso, foram alocados mais recursos financeiros nos convênios. As ONGs compõem parte do atendimento em tempo integral do município. As implicações desse novo formato no desempenho escolar e em outros aspectos devem ser contempladas em estudos futuros.

\section{Considerações Finais}

As três hipóteses apuradas e debatidas na presente oportunidade evidenciam a importância do desenvolvimento de políticas públicas voltadas para crianças provenientes de estratos sociais menos favorecidos. Especificamente, elas conduzem ao pressuposto de que o NSE impacta no desempenho escolar no início da alfabetização, na busca das famílias de baixa renda por locais para deixar suas crianças em segurança, como as ONGs e, mesmo com foco na proteção social, as ações dessas instituições influenciam indiretamente o processo de alfabetização. Considera-se esse argumento, fundamentado nos dados analisados e na literatura que trata dessas questões, como um achado extremamente pertinente dessa investigação, a ser considerado na elaboração de programas voltados à infância. 
Há necessidade de novas pesquisas sobre o tema, a partir de delineamentos longitudinais, qualitativos, dentre outros. Os aspectos protetivos não devem ser desconsiderados nas atividades oferecidas por ONGs e programas de ampliação da jornada escolar. Porém, é preciso que essas ações sejam desenvolvidas de forma a atenuar os efeitos vinculados a questões socioeconômicas, até que políticas econômicas resolvam a desigualdade social no Brasil. Os programas públicos destinados ao atendimento dos estudantes fora da escola têm privilegiado ações a partir de parcerias com instituições sociais. Isso faz com que governos municipais e estaduais não se responsabilizem diretamente com os atendimentos, com a justificativa de apoio a diversas iniciativas, mas sem alocar os aportes financeiros necessários. É imprescindível a elaboração de estratégias com foco na alfabetização para remediar dificuldades futuras dos estudantes no processo de escolarização. Espera-se que este estudo contribua na realização de outras investigações sobre o tema, e quem sabe, com a elaboração e desenvolvimento de políticas públicas de Estado para as crianças.

\section{Referências}

Alves, M. T. G., \& Soares, J. F. (2013). Contexto escolar e indicadores educacionais: condições desiguais para a efetivação de uma política de avaliação educacional. Educação e Pesquisa, 39(1), 177-194. doi: 10.1590/S1517-97022013000100012

Alves, M. T. G., Soares, J. F., \& Xavier, F. P. (2014). Índice socioeconômico das escolas de educação básica brasileiras. Ensaio: Avaliação de Políticas Públicas de Educação, 22(84), 671-704. doi: 10.1590/ S0104-40362014000300005

Alves, P. B., Amparo, D. M., Cardenas, C. J., Chaves, B. M. \& Oliveira, C. B. (2007). Instituições de atendimento socioeducativo à adolescentes em situação de risco do distrito federal: Panorama e perspectivas. Psico, 38(2), 166-173. Recuperado de http:// revistaseletronicas.pucrs.br/ojs/index.php/ revistapsico/article/view/2564/1991

Azevedo, N. C. S., \& Betti, M. (2014). Escolas de tempo integral e ludicidade: Os pontos de vista de alunos do $1^{\circ}$ ano de ensino fundamental. Revista Brasileira de Estudos Pedagógicos, 95(240), 255-275. doi: 10.1590/S2176-66812014000200002

Bardin, L. (2009). Análise de conteúdo. Lisboa: Edições 70.
Brasil. (2007). Decreto Presidencial ñ. 6.094. Dispõe sobre a implementação do Plano de Metas Compromisso Todos pela Educação, pela União, em regime de colaboração com Municípios, Distrito Federal e Estados. Brasília: Diário Oficial da União. Recuperado de http://www.planalto.gov.br/ccivil_03/_ato2007-2010/2007/decreto/d6094.htm

Brasil. Instituto Nacional de Estudos e Pesquisas Educacionais Anísio Teixeira (INEP). (2008). Provinha Brasil: reflexões sobre a prática. Brasília: INEP. Recuperado de http://download.inep.gov.br/ educacao_basica/provinha_brasil/kit/2008/2_semestre/reflexoes_sobre_a_pratica\%202-2008.pdf

Brasil. Instituto Nacional de Estudos e Pesquisas Educacionais Anísio Teixeira (INEP) (2009). Provinha Brasil: Passo a Passo. Brasília: INEP. Recuperado de http://download.inep.gov.br/educacao_basica/ provinha_brasil/kit/2009/1_semestre/passo_a_ passo_1_2009.pdf

Bronfenbrenner, U., \& Morris, P. (2006). The bioecological model of human development. Em W., Damon \& R. M., Lerner Lerner (Editors-in-Chief) \& R. M. Lerner (Volume Ed.), Handbook of child psychology: Vol 1. Theoretical models of human development (pp. 793-828). Hoboken, NJ: Wiley.

Carneiro, R. S., Silva, A. C. V. da., Rizzoli, A. S. G., \& Silva, M. P. da. (2015). Recursos do ambiente familiar e participação dos pais na vida escolar: Um estudo comparativo entre crianças de escola pública e particular. Conexões Psi, 3(1), 49-61. Recuperado de http://apl.unisuam.edu.br/revistas/index.php/ conexoespsi/article/view/574/552

Carnoy, M., Khavenson, T., Fonseca, I., Costa, L., \& Marotta, L. (2015). A educação brasileira está melhorando? Evidências do Pisa e do Saeb. Cadernos de Pesquisa, 45(157), p. 450-485. doi: $10.1590 / 198053143331$

Cooper, H., Valentine, J. C., Ney, B., \& Lindsay, J. J. (1999). Relationships between five after-school activities and academic achievement. Journal of Educational Psychology, 91, 369-378. doi: 10.1037/0022-0663.91.2.369

Fonseca, S. O., \& Namen, A. A. (2016). Mineração em bases de dados do Inep: Uma análise exploratória para nortear melhorias no sistema educacional brasileiro. Educação em Revista, 32(01), p. 133-157. doi: 10.1590/0102-4698140742

Psico-USF, Bragança Paulista, v. 23, n. 3, p. 567-578, jul./set. 2018 
Fundo das Nações Unidas para a Infância (UNICEF). (2008). Redes de aprendiragem: boas práticas de municipios que garantem o direito de aprender. Brasília: INEP.

Fundo das Nações Unidas para a Infância (UNICEF). (2010). Caminhos do Direito de Aprender: boas práticas de 26 municípios que melhoraram a qualidade da educação. Brasília: UNICEF.

Gil, A. C. (2002). Como elaborar projetos de pesquisa. São Paulo: Editora Atlas.

Lahir, B. (1997). Sucesso escolar nos meios populares: As razões do improvável. (R. A. Vasquez \& S. Goldfeder, Trads.) São Paulo: Editora Ática.

Leite, L. H. A., \& Carvalho, P. F. L. de (2016). Educação (de tempo) integral e a constituição de territórios educativos. Educação e Realidade, 41(4), 1205-1226. doi: / 10.1590/2175-623660598

Mahoney, J. L., Cairns, B. D., \& Farmer, T. (2003). Promoting interpersonal competence and educational success trough extracurricular activity participation. Journal of Educational Psychology, 95, 409-418. doi: 10.1037/0022-0663.95.2.409

Mahoney, J. L., Lord, H., \& Carryl, E. (2005). An ecological analysis after-school program participation and the development of academic performance and motivational attributes for disadvantaged children. Child Development, 76(4), 811- 825. doi: 10.1111/j.1467-8624.2005.00879.x

Marturano, E. M., \& Elias, L. C. dos S. (2016). Família, dificuldades no aprendizado e problemas de comportamento em escolares. Educar em Revista, 59, 123-139. doi: 10.1590/0104-4060.44617

Matos, D. A. S, Nogueira, M. A., Resende, T. de F, Nogueira, C. M. M., \& Alves, M. T. G. (2017). Impactos das práticas familiares sobre a proficiência em língua portuguesa e matemática no ensino fundamental. Proposições, 28(1), 33-54. doi: 10.1590/1980-6248-2015-0151

Ministério do Desenvolvimento Social e Combate à Fome/Conselho Nacional de Assistência Social. (2009). Resolução $N^{0}$ 109, de 11 de novembro de 2009. Aprova a Tipificação Nacional de Serviços Socioassistenciais. 2009. Recuperado de http://www. mds.gov.br/suas/resolucao-cnas-no109-2009-tipificacao-nacional-de-servicos-socioassistenciais

Monteiro, R. D. M., \& Santos, A. A. A. (2013). Recursos familiares e desempenho de crianças em compreensão de leitura. Psico, 44(2), 273-279. Recuperado de http://revistaseletronicas.pucrs.br/ revistapsico/ojs/index.php/revistapsico/article/ view/11758/9646

Oliveira, A. G. de, Conceição, M. C. P., Figueiredo, M. R., Campos, J. L. M., Santos, J. N., \& Martins-Reis, V. de O. (2017). Associação entre o desempenho em leitura de palavras e a disponibilidade de recursos no ambiente familiar. Audiology Comunication Research, 21, 1-7. doi: 10.1590/2317-6431-2016-1680

Oliveria, A. C. P., Waldhelm, A. P. S. (2016). Liderança do diretor, clima escolar e desempenho dos alunos: Qual a relação? Revista Ensaio: Avaliação e Políticas Públicas em Educação, 24(93), 824-844. doi: 10.1590/ S0104-40362016000400003

Pena, A. C., \& Soares, T. M. (2016). Fatores de liderança escolar e sua relação com o desempenho. Um estudo com diretores de escolas da rede pública de Minas Gerais/Brasil. REICE. Revista Iberoamericana sobre Calidad, Eficacia y Cambio en Educación, 12(5), 43-59. Recuperado de https://revistas.uam.es/index.php/reice/article/view/2827/3044

Pio, C. A., \& Czernisz, E. C. S. (2015). A educação integral no Mais Educação: Uma análise do programa. Revista Educação UFSM, 40(1), 241-254. doi: 10.5902/1984644415078

Prefeitura Municipal de Belo Horizonte (PBH). (2001). Indicadores de qualidade e custos do atendimento a crianças $e$ adolescentes de 6 a 14 anos em instituições sociais de Belo Horizonte. Belo Horizonte: PBH.

Prefeitura Municipal de Belo Horizonte (PBH). (2010). Resolução Conjunta entre Secretaria Estadual de Educação e Secretaria Municipal de Educação (03/2010). Estabelece normas conjuntas para a realização de Programa de Educação Integral das Redes Públicas Estadual e Municipal de Belo Horizonte e dá outras providências. Recuperado de http://portal6.pbh.gov.br/dom/iniciaEdicao.do?method=D etalheArtigo\&pk $=1037927$

Schimonek, E. M. P. (2015). A qualidade do ensino público e a privatização via Programa Mais Educação. Educação: Teoria e Prática, 25(50), 502-516. doi: 10.18675/1981-8106.vol25.n50.p490-503

Secretaria Municipal de Educação (SMED). (2014). Portaria SMED $n^{\circ}$ 110/2014. Dispõe sobre a transferência e utilização de recursos financeiros às Caixas Escolares da Rede Municipal de Educação. 
Recuperado de http://portal6.pbh.gov.br/dom/ Files/dom04042014-smed-a.rtf

Silva, J. A. de A., \& Silva, K. N. P. (2013). A hegemonia às avessas no Programa Mais Educação. Revista Brasileira de Estudos Pedagógicos, 94(238), 701-720. doi: 10.1590/S2176-66812013000300004

Soares, A. J. G., Brandolin, F., \& Amaral, D. P. do. (2017). Desafios e dificuldades na implementação do Programa Mais Educação: Percepção dos atores das escolas. Educação e Realidade, 42(3), 1059-1079. doi: $10.1590 / 2175-623660490$

Silva, M. G. Q., \& Ehrenberg, M. C. (2017). Atividades culturais e esportivas extracurriculares: influência sobre a vida do discente. Pro-posições, 18(1), 15-32. doi: 10.1590/1980-6248-2015-0055

Springer, K., \& Diffily, D. (2012). The relationship between intensity and breadth of after-school program participation and academic achievement: Evidence from a short-term longitudinal study. Journal of Community Psychology, 38(7), 785-798. doi: 10.1002/jcop. 21478

Vygotsky, L. S. (2003). A formação social da mente. São Paulo: Martins Fontes.

Recebido em: 02/09/2017

Reformulado em: 07/01/2018

Aprovado em: 20/02/2018

Sobre o autor:

Neyfsom Carlos Fernandes Matias é graduado em Psicologia pela Pontifícia Universidade Católica de Minas Gerais, especialista em Políticas Públicas pelo Departamento de Ciência Política da Universidade Federal de Minas Gerais (UFMG), mestre e doutor em Psicologia pela UFMG e professor do Departamento de Psicologia da Universidade Federal de São João Del-Rei.

E-mail: neyfsom@ufsj.edu.br

ORCID: https://orcid.org/0000-0001-9064-2282

Contato com o autor:

Praça Dom Helvécio, 74 - sala 2,14 - Departamento de Psicologia

São João Del-Rei-MG, Brasil

CEP: 36301-160 